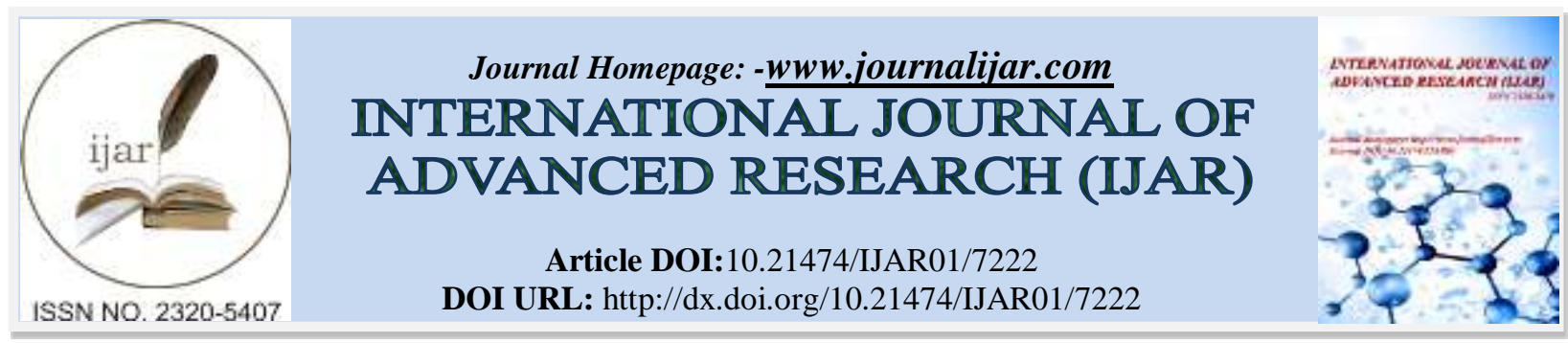

RESEARCH ARTICLE

\title{
A DESCRIPTIVE STUDY TO ASSESS COMPETENCIES OF STAFF NURSES RELATED TO FLUID AND ELECTROLYTE IMBALANCES.
}

Roohi Elizabeth Peter.

Clinical Instructor, KGMU Institute of Nursing, Lucknow- 226003, Uttar Pradesh.

\section{Manuscript Info}

Manuscript History

Received: 06 April 2018

Final Accepted: 08 May 2018

Published: June 2018

Keywords:-

Competencies, Knowledge,

Interpretation, Staff Nurses, Fluid and

Electrolyte Imbalances.

\begin{abstract}
Body fluids and electrolytes play an important role in homeostasis. Homeostasis is the state of equilibrium in the internal environment of the body. Disturbances in fluid and electrolytes are among the most common clinical problems encountered in the intensive care units. A descriptive study was conducted to assess competencies of staff nurses (in terms of knowledge and interpretation) related to fluid and electrolyte imbalances in a selected hospital, Ludhiana, Punjab. A qualitative research approach and non-experimental descriptive design was adopted for the study. Conceptual framework was based on Three Phase Learning Theory by Fitts and Posner, 1967. Data was collected by using a Competency Assessment Tool of Fluid and Electrolyte Imbalances (CATFEI) which was found reliable $(\mathrm{r}=0.77)$. The collected data from 120 staff nurses selected by non- probability purposive sampling technique was analyzed using descriptive and inferential statistics. The study revealed that maximum staff nurses (41.67\%) had average level of competency. In terms of knowledge, $35.83 \%$ staff nurses had below average level of knowledge and in terms of interpretation, $44.17 \%$ staff nurses had below average level of interpretation. A moderate positive correlation (0.47) was found between knowledge and interpretation. Professional qualification had significant relationship with interpretation (at $\mathrm{p}<0.05$ ). Maximum deficit in terms of knowledge and interpretation was in risk for developing hypernatremia (87.5\%) and nursing intervention for hyponatremia (89.17\%) respectively. It was concluded that maximum deficit was in the areas of electrolyte imbalances. Therefore, an InService Education was conducted for the staff nurses of the selected hospital.
\end{abstract}

Copy Right, IJAR, 2018,. All rights reserved.

\section{Introduction:-}

"Water is essential for life, and maintaining the correct balance of fluid in the body is crucial to health" [1]. Fluid balance is a term used to describe the balance of the input and output of fluids in the body to allow metabolic processes to function correctly [2].

Some fluid and electrolyte imbalances are directly caused by illness or disease (e.g. burns, heart failure). At times, therapeutic measures (e.g. IV fluid replacement, diuretics) cause or contribute to fluid and electrolyte imbalances 
[3]. It is the responsibility of the nurse caring for a patient to ensure observations and fluid balance are recorded in a timely manner, with any abnormal findings documented and reported to the nurse in charge [4].

Recent studies have reported that fluid and electrolyte imbalances are associated with increased morbidity and mortality among critically ill patients. To provide optimal care, health care providers should be familiar with the principles and practice of fluid and electrolyte physiology and pathophysiology [5].

Competency is defined as "The ability to demonstrate the application of knowledge, understanding, practical and thinking skills to achieve effective performance in a professional role. This involves problem solving and being sufficiently flexible to meet changing demands." [6].

\section{Need of the study:-}

It is the responsibility of the nurse caring for a patient to ensure observations and fluid balance are recorded in a timely manner, with any abnormal findings documented and reported to the nurse in charge [7]. Recent studies have reported that fluid and electrolyte imbalances are associated with increased morbidity and mortality among critically ill patients. To provide optimal care, health care providers should be familiar with the principles and practice of fluid and electrolyte physiology and pathophysiology. [8]

Competencies are an important part of a continual process to ensure that the organization provides a high-quality care to its customers and patients. Since many diseases and their treatments have the ability to affect fluid and electrolyte balance. It is important for the nurses to anticipate the potential for alterations in fluid and electrolyte balance associated with certain disorders and medical therapies, to recognize the signs and symptoms of imbalances, and to intervene with the appropriate action. Hence the investigator felt the need for assessing and improving competencies of staff nurses in identifying and dealing patients with fluid and electrolyte imbalances.

\section{Research Problem:-}

A Descriptive Study to Assess Competencies of Staff Nurses related to Fluid and Electrolyte Imbalances in a Selected Hospital, Ludhiana, Punjab.

\section{Objectives:-}

1. To assess the levels of competencies of staff nurses related to fluid and electrolyte imbalances.

2. To assess the levels of competencies of staff nurses in terms of knowledge and interpretation related to fluid and electrolyte imbalances.

3. To find out correlation between knowledge and interpretation related to fluid and electrolyte imbalances.

4. To ascertain the relationship of competencies of staff nurses related to fluid and electrolyte imbalances with selected personal \& professional factors.

5. To ascertain the relationship of competencies in terms of knowledge and interpretation of staff nurses related to fluid and electrolyte imbalances with selected personal \& professional factors.

6. To identify deficits in competencies of staff nurses related to knowledge and interpretation of fluid and electrolyte imbalances.

Research Methodology:-

Research approach:-

Quantitative (non- experimental) research approach

\section{Research design:-}

Descriptive design

\section{Setting of the study:-}

Critical Care areas of Christian Medical College and Hospital, Ludhiana, Punjab.

\section{Sampling technique:-}

Non- Probability Purposive Sampling Technique

\section{Sampling size:-}

120 staff nurses working in adult critical care areas 


\section{Description of the tool:-}

A Competency Assessment Tool of Fluid and Electrolyte Imbalances (CATFEI) was developed to assess the competencies of staff nurses in terms of knowledge and interpretation of fluid and electrolyte imbalances. The research tool consists of two parts:

Part I: Personal \& Professional Information

Part II: Structured questionnaire on fluid and electrolyte imbalances. It had two sections with a total of 40 multiple choice questions. Each correct answer was awarded a score of one and wrong answer zero.

1. Section A: Items related to knowledge of fluid and electrolyte imbalances.

2. Section B: Items related to interpretation of fluid and electrolyte imbalances.

\section{Reliability of the tool:-}

Reliability of the tool was computed by applying split half (odd-even) method and was calculated by Karl Pearson's co-efficient correlation and Spearman Brown Prophecy formula and was found $\mathbf{r}^{\prime}=\mathbf{0 . 7 7}$.

\section{Results:-}

The analysis was done using descriptive and inferential statistics.

Finding related to sample characteristics:-

Maximum staff nurses were in the age group of $26-30$ years $(49.17 \%), 74.17 \%$ were females, $68.33 \%$ did GNM, $42.5 \%$ had a total of $>5$ years of total professional experience, $69.17 \%$ were working in Intensive Care Units and $39.17 \%$ got information related to fluid and electrolyte imbalances through textbooks/classroom teachings (Table $1)$.

Findings related to competencies in terms of knowledge and interpretation of staff nurses related to fluid and electrolyte imbalances:-

Maximum staff nurses $41.67 \%$ were found to have average level of competency (Fig 1). In terms of knowledge, maximum staff nurses $35.83 \%$ had below average level of knowledge. In terms of interpretation, maximum staff nurses $44.17 \%$ had below average level of interpretation.

Findings related to correlation of knowledge and interpretation:-

The mean of knowledge score was 10.73 and mean of competency score was 9.87. A moderate positive correlation $(0.47)$ between knowledge and interpretation was found.

Findings related to relation of competencies of staff nurses related to fluid and electrolyte imbalances with various personal and professional factors:-

Highest mean interpretation score (11.86) was found among staff nurses who did Post Basic B.Sc. Nursing. Analysis was done with analysis of variance. It was statistically significant at $p<0.05$ level which shows that professional qualification had an impact on interpretation score of staff nurses related to fluid and electrolyte imbalances.

Findings related to Deficits in Competencies of Staff Nurses related to Fluid and Electrolyte Imbalances:It was found that staff nurses had maximum competency score in interpretation of fluid imbalances and were least competent to interpret electrolyte imbalances (Table 2 \& Fig. 2)

In terms of knowledge, risk for developing hypernatremia in electrolyte imbalances has maximum deficit (87.5\%) (Table 3) whereas in terms of interpretation, nursing intervention for hyponatremia in electrolyte imbalances has maximum deficit (89.2\%) (Table 4). Hence, from the above findings, it was concluded that maximum deficit was in the areas of electrolyte imbalances.

Table 1:-Frequency \& Percentage Distribution of Staff Nurses according to Personal and Professional Factors

\begin{tabular}{|c|c|c|}
\hline \multirow[b]{2}{*}{ Personal and Professional Factors } & \multicolumn{2}{|c|}{ Staff Nurses $(\mathrm{N}=120)$} \\
\hline & $\mathbf{f}$ & Percentage $(\%)$ \\
\hline $\begin{array}{ll}\text { 1. } & \text { Age (in years) } \\
\text { a) } & 21-25\end{array}$ & 34 & 28.33 \\
\hline b) $\quad 26-30$ & 59 & 49.17 \\
\hline
\end{tabular}




\begin{tabular}{|c|c|c|c|}
\hline c) & $31-35$ & 16 & 13.33 \\
\hline d) & $>35$ & 11 & 9.17 \\
\hline 2. & Gender & & \\
\hline a) & Male & 31 & 25.83 \\
\hline b) & Female & 89 & 74.17 \\
\hline 3. & Professional qualification: & & \\
\hline a) & Basic B.Sc. Nursing & 31 & 25.83 \\
\hline b) & Post Basic B.Sc. Nursing & 7 & 5.83 \\
\hline c) & GNM & 82 & 68.33 \\
\hline 4. & Professional experience: & & \\
\hline a) & 6 months- 1 year & 9 & 7.5 \\
\hline b) & $1-3$ years & 32 & 26.67 \\
\hline c) & $3-5$ years & 28 & 23.33 \\
\hline d) & More than 5 years & 51 & 42.5 \\
\hline 5. & Area of work & & \\
\hline a) & Intensive Care Unit & 83 & 69.17 \\
\hline b) & High Dependency Unit & 37 & 30.83 \\
\hline 6. & $\begin{array}{l}\text { Source of learning related to fluid and electrolyte } \\
\text { imbalances }\end{array}$ & & \\
\hline a) & Textbook/classroom teachings & 47 & 39.17 \\
\hline b) & Self-study/electronic media/internet & 27 & 22.5 \\
\hline c) & In-service education & 14 & 11.67 \\
\hline d) & Clinical teaching/ rounds & 32 & 26.67 \\
\hline
\end{tabular}

Fig 1:-Percentage Distribution of Staff Nurses according to Levels of Competencies related to Fluid and Electrolyte Imbalances.

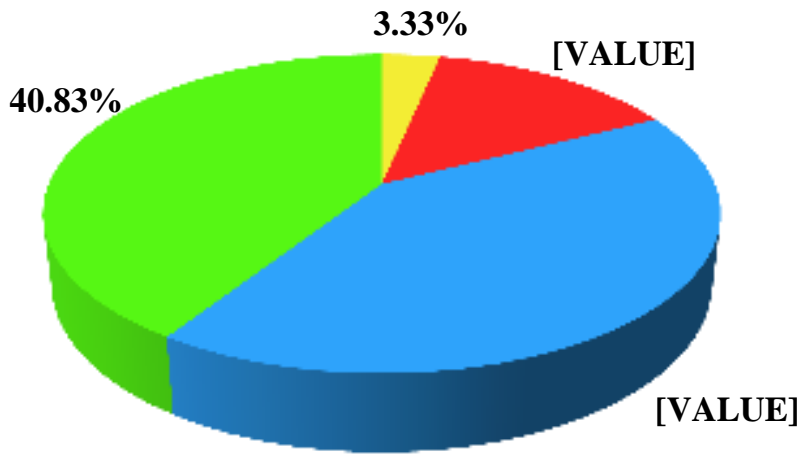

KEY

High level

- Moderate level

$\because$ Average level

Low level

\section{LEVELS OF COMPETENCIES}

Table 2:-Mean, Mean Percentage and Rank Order of Competency Score according to Areas of Competency related to Fluid and Electrolyte Imbalances

\begin{tabular}{|lcccc|}
\hline Areas of & \multicolumn{4}{c|}{ Competency Score (N=120) } \\
Competency & Scores & Mean & Mean \% & Rank Order \\
\hline Knowledge & & & & \\
Fluid Imbalances & 10 & 5.33 & 53.33 & 3 \\
Electrolyte imbalances & 10 & 5.4 & 54.00 & 2 \\
Interpretation & & & & \\
Fluid Imbalances & 9 & 5.45 & 60.56 & 1 \\
Electrolyte Imbalances & 11 & 4.42 & 40.18 & 4 \\
\hline
\end{tabular}

Maximum score $=\mathbf{4 0}$

Minimum score $=0$ 
Fig. 2:-Percentage Distribution of Competency Score of Staff Nurses according to Areas of Competency related to Fluid and Electrolyte Imbalances.

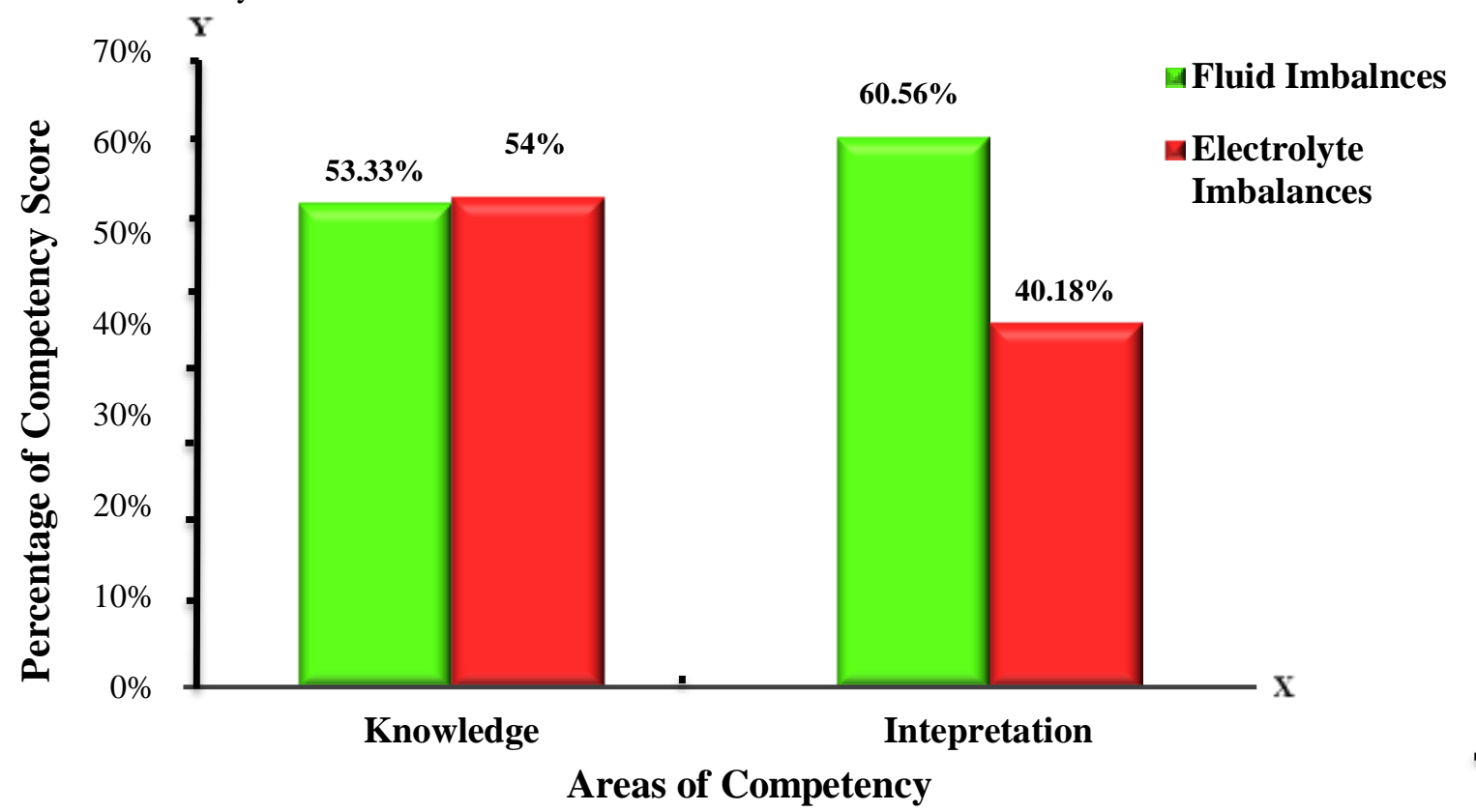

Table 3:-Frequency, Mean, Mean Percentage and Rank Order of Staff Nurses according to Deficit in Items related to Knowledge of Fluid and Electrolyte Imbalances

\begin{tabular}{|c|c|c|c|c|c|}
\hline \multirow{2}{*}{\multicolumn{2}{|c|}{\begin{tabular}{l|l} 
& \\
Knowledge Items
\end{tabular}}} & \multicolumn{4}{|c|}{ Staff Nurses with Deficit $(\mathrm{N}=120)$} \\
\hline & & \multirow[t]{2}{*}{ f } & \multirow[t]{2}{*}{ mean } & \multirow[t]{2}{*}{ mean \% } & \multirow[t]{2}{*}{$\begin{array}{l}\text { Rank } \\
\text { Order }\end{array}$} \\
\hline A & FLUID IMBALANCES & & & & \\
\hline & $\begin{array}{l}\text { 1. The process of water movement through a } \\
\text { semipermeable membrane from an area of low solute } \\
\text { concentration to an area of higher concentration is } \\
\text { known as }\end{array}$ & 28 & 0.233 & 23.3 & 17 \\
\hline & $\begin{array}{l}\text { 2. Shift of fluid from the vascular space to an area } \\
\text { where it is not available to support normal } \\
\text { physiologic process is known as }\end{array}$ & 75 & 0.625 & 62.5 & 4 \\
\hline & $\begin{array}{l}\text { 3. The movement of molecules from an area of higher } \\
\text { concentration to an area of low concentration is } \\
\text { known as }\end{array}$ & 32 & 0.267 & 26.7 & 16 \\
\hline & 4. The consequence of third space fluid loss is & 49 & 0.408 & 40.8 & 12 \\
\hline & 5. The manifestation of hypovolemia is & 32 & 0.267 & 26.7 & 16 \\
\hline & $\begin{array}{l}\text { 6.All are the manifestations of fluid volume excess } \\
\text { EXCEPT }\end{array}$ & 87 & 0.725 & 72.5 & 3 \\
\hline & 7. Orthostatic Hypotension refers to drop of & 55 & 0.458 & 45.8 & 8 \\
\hline & $\begin{array}{l}\text { 8. The patient is admitted to a hospital with a hematocrit } \\
\text { of } 56 \% \text { and a serum sodium level of } 152 \mathrm{mEq} / \mathrm{L} \text {. The } \\
\text { cause for these findings is }\end{array}$ & 65 & 0.542 & 54.2 & 6 \\
\hline & 9. All are isotonic fluids EXCEPT & 101 & 0.842 & 84.2 & 2 \\
\hline & $\begin{array}{l}\text { 10. The initial fluid of choice for managing hypovolemic } \\
\text { shock is }\end{array}$ & 36 & 0.30 & 30 & 15 \\
\hline \multicolumn{6}{|c|}{ ELECTROLYTE IMBALANCES } \\
\hline & $\begin{array}{l}\text { 11. The electrolyte disturbance that leads to an ECG with } \\
\text { a tall, tented, ' } T \text { ' wave is }\end{array}$ & 50 & 0.416 & 41.6 & 11 \\
\hline & $\begin{array}{l}\text { 12. The food product that contains lowest levels of } \\
\text { potassium is }\end{array}$ & 55 & 0.458 & 45.8 & 8 \\
\hline
\end{tabular}




\begin{tabular}{|l|l|l|l|l|}
\hline $\begin{array}{l}\text { 13. The client has been vomiting and has had numerous } \\
\text { episodes of diarrhea. The laboratory test that should } \\
\text { be monitored is }\end{array}$ & 47 & 0.392 & 39.2 & 13 \\
\hline $\begin{array}{l}\text { 14. The patient who has a potassium level of 5.9 mEq/L } \\
\text { will be }\end{array}$ & 39 & 0.325 & 32.5 & 14 \\
\hline $\begin{array}{l}\text { 15. The normal serum magnesium level is } \\
\text { 16. The drug of choice for Hypermagnesemia is } \\
\text { intravenous }\end{array}$ & 57 & 0.475 & 47.5 & 7 \\
\hline $\begin{array}{l}\text { 17. The normal serum sodium level is } \\
\text { 18. The patient at risk for developing hypernatremia will } \\
\text { be a }\end{array}$ & 105 & 0.45 & 45 & 9 \\
\hline 19. The normal serum calcium level is & 67 & 0.578 & 57.8 & 18 \\
\hline $\begin{array}{l}\text { 20. client with hypoparathyroidism complains of } \\
\text { numbness and tingling in his fingers and around the } \\
\text { mouth. The nurse would assess for }\end{array}$ & 52 & 0.433 & 43.3 & 10 \\
\hline
\end{tabular}

Table 4:-Frequency, Mean, Mean Percentage and Rank Order of Staff Nurses according to Deficit in Items related to Interpretation Fluid and Electrolyte Imbalances

\begin{tabular}{|l|l|l|l|l|l|}
\hline & Staff Nurses with Deficit (N=120) \\
\hline Interpretation Items & $\mathbf{f}$ & mean & Mean \% & $\begin{array}{l}\text { Rank } \\
\text { order }\end{array}$ \\
\hline A. & Fluid imbalances & & & & \\
\hline & 21.Assessment of deficient fluid volume & 30 & 0.25 & 25 & 19 \\
\hline & 22.Nursing diagnosis for excess fluid volume & 52 & 0.433 & 43.3 & 13 \\
\hline & 23.Assessment of excess fluid volume. & 64 & 0.533 & 53.3 & 9 \\
\hline & 24.Assessment of third space fluid shift & 70 & 0.583 & 58.3 & 6 \\
\hline & 25.Assessment of dehydration & 48 & 0.40 & 40 & 15 \\
\hline & 26.Nursing interventions of deficient fluid volume & 31 & 0.258 & 25.8 & 18 \\
\hline & 27.Interventions for deficient fluid volume & 34 & 0.283 & 28.3 & 17 \\
\hline & 28.Nursing intervention of fluid volume excess & 53 & 0.442 & 44.2 & 12 \\
\hline & 29.Clinical situation related to fluid shift & 44 & 0.367 & 36.7 & 16 \\
\hline B & & & & \\
\hline & 30.Nursing intervention for hyponatremia & 107 & 0.892 & 89.2 & 1 \\
\hline & 31.Assessment of hyponatremia & 71 & 0.592 & 59.2 & 5 \\
\hline & $\begin{array}{l}\text { 32.The client which might need dietary sodium } \\
\text { restriction }\end{array}$ & 50 & 0.417 & 41.7 & 14 \\
\hline & 33.ECG changes because of hypokalemia & 95 & 0.792 & 79.2 & 2 \\
\hline & 34.Nursing intervention for hypokalemia & 66 & 0.55 & 55 & 8 \\
\hline & 35.The assessment finding of hypocalcemia & 67 & 0.558 & 55.8 & 7 \\
\hline & 36.ECG changes because of hypocalcemia & 66 & 0.55 & 55 & 8 \\
\hline & 37.Assessment of hypocalcemia & 57 & 0.475 & 47.5 & 10 \\
\hline & 38.Clinical manifestation of hypocalcemia & 79 & 0.658 & 65.83 & 3 \\
\hline & 39.Nursing intervention for hypomagnesemia & 78 & 0.65 & 65 & 4 \\
\hline & $\begin{array}{l}\text { 40.The nurse evaluates hypermagnesemia in a client who } \\
\text { has }\end{array}$ & 54 & 0.45 & 45 & 11 \\
\hline
\end{tabular}

\section{Conclusion:-}

Disturbances in fluid and electrolytes are among the most common clinical problems encountered in the intensive care unit (ICU). To provide optimal care, health care providers should be familiar with the principles and practice of fluid and electrolyte physiology and pathophysiology. The study concluded that most of the staff nurses had an average level of competency related to fluid and electrolyte imbalances. Staff nurses were least competent to interpret electrolyte imbalances. Implementation \& evaluation of ongoing in-service education on competencies regarding fluid and electrolyte imbalances for staff nurses posted in critical care areas and general wards was 
recommended to improve their competencies regarding fluid and electrolyte imbalances. This will ensure immediate identification and management of such imbalances and quality assurance in health.

\section{Discussion:-}

The analysis of the data revealed that maximum staff nurses had average $(41.67 \%)$ and low $(40.83 \%)$ levels of competencies related to Fluid and Electrolyte Imbalances. In terms of knowledge, maximum staff nurses 35.83\% had below average level of knowledge and in terms of interpretation, maximum staff nurses $44.17 \%$ had below average level of interpretation. These findings were supported by Van De Vreede et al (2008) ${ }^{9}$ who states that nurses could make medication errors because they do not have sufficient knowledge and practice about intravenous potassium administration and medication safety. These errors may cause fatalities and incidents. The findings were also supported by Mogileeswari P, Ruth Grace M. $(2016)^{[10]}$ who states that 15 staff nurses $(15 \%)$ had adequate knowledge, $62(62 \%)$ had moderately adequate knowledge and 23(23\%) had inadequate knowledge. The study also showed practice regarding fluid and electrolyte replacement therapy for patient with burns among nurses. 37(37\%) had safe practice, $42(42 \%)$ had moderately safe practice and $21(21 \%)$ had unsafe practice.

The relationship between knowledge and interpretation was found to be moderate positive (0.47) for the present study. This was supported by Alex $\mathbf{J}(2010){ }^{[11]}$ who revealed that there exist a positive correlation between knowledge and practices of staff nurses regarding anticoagulant drugs. This was also supported by Wynne N, Brand S \& Smith R (1997) ${ }^{[12]}$ who suggests that scientific knowledge gives nurses greater potential in understanding and performing nursing care.

\section{Acknowledgement:-}

Words cannot express my heartiest gratitude, reverence and thankfulness to my supervisor Mrs. Ritu P. Naihar, Associate Professor, and co-supervisor Mrs. Sapna D. Malviya, Assistant Professor, Medical Surgical Nursing CMC \& H Ludhiana for their commitment, meticulous advice, outstanding organizational abilities and creative ideas which was a valuable asset to me during various phases of research process. I am indebted to Professor Mrs. Ponnamma R. Singh, Principal, College of Nursing for granting permission and providing all needed support to conduct the study. I am deeply obliged to Mrs. Renuka Chauhan, Professor and Head of the Department, Medical Surgical Nursing, for her keen interest in solving my problems whenever they emerged, expert advices, and constant encouragement to make this study a successful learning experience.

\section{References:-}

1. Welch K. (2010): Fluid Balance. Learning Disability Practice: 13 (6): 33-38.

2. Anderson DM. (2005): Mosby's Medical, nursing, and allied health dictionary, $6^{\text {th }}$ edition, St Louis, Mosby.

3. Huether SE, McCance K. (2004): Understanding pathophysiology, $3^{\text {rd }}$ edition, St. Louis, Mosby.

4. Scales K, Pilsworth J. (2008): The importance of fluid balance in clinical practice. Nursing Standard; 22: 47, 50-57.

5. Lee JW. (2010): Fluid and electrolyte disturbances in critically ill patients. Electrolyte Blood Pressure. December; 8(2):72-81.

6. Irish Research Nurses Network; Clinical Research Nurse Competency Pack. November 2015.

7. Scales K, Pilsworth J. The importance of fluid balance in clinical practice. Nursing Standard 2008; 22: 47, 5057.

8. Lee JW. Fluid and electrolyte disturbances in critically ill patients. Electrolyte Blood Pressure. December 2010; 8(2):72-81.

9. Van De Vreede, M.A., Wilson, S.G. and Dooley, M.J. (2008): Intravenous potassium chloride prescribing and administration practices in Victoria: An observational study. Medical Journal of Australia, 189(10):575-577

10. Mogileeswari P, Ruth Grace M. (2016): Knowledge and practice regarding fluid and electrolyte replacement therapy for patient with burns. International Journal of Multidisciplinary Research and Development. 3(4); 217 220.

11. Alex J. (2013): An exploratory study to assess the knowledge and practices of staff nurses regarding anticoagulant drugs used in a selected hospital, Ludhiana, Punjab. Unpublished Master of Science in Nursing Dissertation, BFUHS.

12. Wynne N, Brand S \& Smith R. (1997): Incomplete holism in pre-registration nurse education. Journal of advanced nursing; 26: 470-74. 